Emission Trading and the Role of Learning-by-doing

Spillovers in the 'Bottom-up'

Energy-System ERIS Model

Leonardo Barreto and Ger Klaassen

RR-04-008

July 2004 



\section{Emission Trading and the Role of Learning- by-doing Spillovers in the 'Bottom-up' Energy-System ERIS Model}

Leonardo Barreto

Ger Klaassen

RR-04-008

July 2004

Reprinted from Int. J. Energy Technology and Policy, 2(1/2):70-95 (2004).

International Institute for Applied Systems Analysis - Schlossplatz 1 - A-2361 Laxenburg - Austria Tel: (+43 2236) 807 •Fax: (+43 2236) 71313 • E-mail: publications@iiasa.ac.at•Web: www.iiasa.ac.at 
Research Reports, which record research conducted at IIASA, are independently reviewed before publication. Views or opinions expressed herein do not necessarily represent those of the Institute, its National Member Organizations, or other organizations supporting the work.

Reprinted with Permission from Int. J. Energy Technology and Policy, 2(1/2):70-95 (2004).

Copyright (c) 2004 Inderscience Enterprises Ltd.

All rights reserved. No part of this publication may be reproduced or transmitted in any form or by any means, electronic or mechanical, including photocopy, recording, or any information storage or retrieval system, without permission in writing from the copyright holder. 


\title{
Emission trading and the role of learning-by-doing spillovers in the 'bottom-up' energy-system ERIS model
}

\section{Leonardo Barreto* and Ger Klaassen}

Environmentally Compatible Energy Strategies (ECS), International Institute for Applied Systems Analysis (IIASA), Schlossplatz 1. A-2361, Laxenburg, Austria

Fax: +43-2236-807488

E-mail: barreto@iiasa.ac.at

${ }^{*}$ Corresponding author

\begin{abstract}
In this paper, using the 'bottom-up' energy-system optimisation ERIS model, we examine the effects of emission trading on technology deployment, emphasising the role of technology learning spillovers. That is, the possibility that the learning accumulated in a particular technology in a given region may spill to other regions as well, leading to cost reductions there also. The effects of different configurations of interregional spillovers of learning in ERIS and the impact of the emission trading mechanism under those different circumstances are analysed. Including spatial spillovers of learning allows capturing the possibility that the imposition of greenhouse gas emission constraints in a given region may induce technological change in other regions, such as developing countries, even if the latter regions do not face emission constraints. Our stylised results point out the potential benefits of sound international cooperation between industrialised and developing regions on research, development, demonstration and deployment (RD3) of clean energy technologies and on the implementation of emission trading schemes.
\end{abstract}

Keywords: technology learning; emission trading; spillovers.

Reference to this paper should be made as follows: Barreto, L. and Klaassen, G. (2004) 'Emissions trading and the role of learning-by-doing spillovers in the 'bottom-up' energy-systems ERIS model', Int. J. Energy Technology and Policy, Vol. 2, Nos. 1/2, pp.70-95.

Biographical notes: Leonardo Barreto holds degrees in Electrical Engineering (BSc, MSc) from the National University of Colombia and a $\mathrm{PhD}$ in Engineering from the Swiss Federal Institute of Technology Zurich (ETHZ). From 1994 to 1996 he worked for the Energy and Mines Planning Unit (UPME) of the Colombian Energy Ministry and the National University of Colombia. From 1997 to 2001 he was research assistant in the Energy Modelling Group at the Paul Scherrer Institute in Switzerland. He is currently a research scholar in the Environmentally Compatible Energy Strategies Project (ECS) at the International Institute for Applied Systems Analysis. He has been involved in development and application of energy-system models (e.g. MARKAL, ERIS) and participated in several projects, among others, on energy technology dynamics (TEEM and SAPIENT) funded by the European Commission, on carbon trading for CRIEPI (Japan), on analysing the 'hydrogen economy' for TEPCO (Japan) and examining the role of carbon capture and sequestration technologies funded by Carnegie Mellon University (US). 
Ger Klaassen holds a $\mathrm{PhD}$ in Economics from the Free University Amsterdam. $\mathrm{He}$ is currently a research scholar in the Environmentally Compatible Energy Strategies Project (ECS) at the International Institute for Applied Systems Analysis (IIASA) conducting research on the development of energy infrastructures, endogenous technological progress, and economic instruments. Previously he worked at the Environment Directorate General of the European Commission, IIASA's Transboundary Air Pollution Project and the Free University in Amsterdam. He has also been Visiting Professor in Environmental Economics at Colorado College (USA).

\section{Introduction}

Technological change is, in the long run, one of the main mechanisms to comply with environmental constraints. Development and diffusion of cleaner technologies increase the ability of the system to comply with tighter constraints in the future and may have positive ancillary economic effects [1]. Thus, fostering them is an important consideration when conceiving environmental policies.

The climate change issue is no exception. Although many short-term aspects are of key importance in designing climate policy instruments, their ability to encourage technological pathways that drive to a low-carbon energy system in the long run constitutes an essential aspect. The choice and design of such instruments must, therefore, take into account the influence of energy technology dynamics mechanisms.

Emission trading has been proposed as one of the flexibility mechanisms to comply with greenhouse gas (GHG) emission reductions. It gives parties with expensive in-house mitigation options the possibility of profiting from cheaper alternatives available somewhere else by buying emission permits. The implementation of a market of emission permits would exert an influence in the technological trajectory of the global energy system. Thus, it becomes important to examine the effects of trade on the stimulation of the development and introduction of low-carbon and more efficient energy technologies.

One of the factors likely to have an influence on the action of emission trading is technology spillover. Technology spillovers across countries and world regions constitute an important mechanism for diffusion of technologies in the global markets. These spillovers occur through different channels such as foreign direct investment, international flows of goods, knowledge and people, international cooperation on R\&D and technology transfer, among others.

Although a number of studies have examined knowledge spillovers or learning-by-doing effects, empirical studies treating learning-by-doing spillovers are rare. An exception is the work of [2], who examined learning-by-doing spillovers in the semiconductor industry. Their findings support the existence of spillovers between firms in that industry. Those spillovers appear to be international in scope, with learning spilling both between firms in different countries as well as in a given country. Firms also appear to learn more from their own cumulative production than from that of other firms but the cumulative production of rest-of-the-world firms is much larger than that of a single firm. This kind of empirical analysis, however, is still to be conducted for energy technologies.

Thus, although their role in the adoption of technologies has been recognised, the magnitude and geographical scope of spillovers for different technologies and regions are 
difficult to quantify [3] and their incorporation in energy-systems models is still rudimentary $[4,5]$.

Here, we examine the effects of emission trading on technology deployment, emphasising the role of spillovers of technology learning. That is, the possibility that the learning accumulated in a particular technology in a given region may spill to other regions as well, leading to cost reductions also there. The analysis is carried out using a multi-regional version of the 'bottom-up' energy-system optimisation ERIS model [6,7]. The effects of different configurations of interregional spillovers of learning in ERIS and the impact of the emission trading mechanism under those different circumstances are analysed.

We highlight the role of spillovers of learning across regions as an important mechanism to be considered when modelling the interaction between climate policy instruments and technological change. Including spatial spillovers of learning allows capturing the possibility that the imposition of greenhouse gas emission constraints in a given region may induce technological change in other regions, such as developing countries, even if the latter regions do not face emission constraints. As a consequence, the impact of emission trading on technology diffusion is also influenced by the presence or absence of technology spillovers.

In order to analyse the influence of learning-by-doing spillovers in energy technologies we consider different spatial scales of the learning process and compare the resulting technology mix and emission paths for different cases. The learning configurations examined here have only an illustrative purpose, since they assume that spillovers between two given regions are either full or nonexistent. Thus, they do not reflect the real, more complex 'topology' of the learning networks of the technologies, particularly in an increasingly globalised world where more multi-national energy technology suppliers operate at the international level. Still, examining such an hypothetical learning configurations enables us to gain insights into the consequences of emission trading under different assumptions on the spatial scale (global or regional) of the learning process.

\section{Technology learning and spillovers}

In this section, a brief description of the learning, or experience, curve concept is presented, which represents an empirical manifestation of learning processes within the technological context, central to the analyses performed in this work.

Learning, or experience, processes have been identified in many different social and economic activities, even driving to the conception of society as a learning system [8]. In line with this notion, technological change can be seen as a cumulative social learning process building upon accumulation of knowledge and experience [9]. Learning is, indeed, one of the key drivers of technological change and diffusion of innovations.

We consider here the typical formulation of learning, or experience curves, describing the specific investment cost of a given technology as a function of the cumulative capacity, a proxy for the accumulated experience [10]. The curve reflects the fact that some technologies experience declining costs as a result of their increasing adoption due to, among others, learning-by-doing (manufacture) and learning-by-using (use) effects. The specific investment cost (SC) is formulated as: 


$$
\mathrm{SC}(\mathrm{CC})=a^{*} \mathrm{CC}^{-b}
$$

where CC is Cumulative capacity, $b$ is Learning index and $a$ is Specific cost at unit cumulative capacity.

Usually, instead of the learning index $b$, the learning rate (LR), i.e. the rate at which the cost declines each time the cumulative production doubles, is specified as:

$$
\mathrm{LR}=1-2^{-b}
$$

For instance, an LR of $10 \%$ means that the costs are reduced in $10 \%$ for each cumulative capacity doubling.

The experience curve represents the aggregate effects of many different incremental changes, which, when compounded, are important drivers of technological progress. Change of this nature takes place as an evolutionary process involving significant experimental effort that proceeds in a cumulative way as the stock of practical experience grows [11].

The learning curve has, however, a phenomenological nature, in the sense that the experience effect can, but not necessarily will, become manifest. Thus, learning curves do not exist for all the technologies. A number of forces must intervene to make the learning effect operational. In particular, it is clear that deliberate and continuous efforts are fundamental. Without them, the learning potential of a given activity (or technology) would not be 'tapped', knowledge will not be accumulated and the curve may not materialise.

Technology learning has an important spatial dimension reflected by the action of spillovers. As stated in [12], "technological change is fundamentally a form of learning, and learning is a network phenomenon". Networks of social actors at the national or international level allow exchanging information about, and continuous experimentation with, technologies and constitute an essential element for the diffusion of innovations. At the collective level, learning proceeds through network feedbacks between co-operative and competitive agents [13]. Hence, networks encourage learning from others, stimulate compatibility and mutual dependence between actors and help, through sharing of experiences, to reduce the risk and fears of adoption of the new technology [14]. Technology spillovers occur between nodes of these networks of social actors.

Learning spillovers have received some attention in the literature, in particular at the firm level. In such a context, the presence of learning spillovers appears to produce conflicting effects [15]. On the one hand, spillovers have an efficiency effect, increasing the pace of the cost reduction, since firms benefit from their rivals' learning processes. On the other hand, spillovers provide a disincentive for firms to expand their output and reduce costs, since they cannot capture all the benefits of their learning-by-doing efforts. Analyses carried out in [15] concluded that the efficiency effect appears to dominate given that firms are not likely to reduce their output, because output generates revenues.

On the basis of these arguments, Duke and Kammen [16] analyse the learning process of emerging, currently expensive but promising, energy technologies. According to their analysis, the disincentive effect mentioned above, together with the so-called market power effect, where imperfect spillovers confer firms cost advantages over potential entrants, causes firms' output to fall below the social optimum, thus providing a rationale for government intervention, for instance through market transformation programmes, 'buydown' programmes, the removal of market barriers, or a combination of them [17], in order to stimulate the successful diffusion of clean energy technologies. 
To the extent that such a strategic behaviour occurs also between different world regions, there could be a lack of incentives for countries to pay for the 'learning investments' [18] of cleaner energy technologies that are currently expensive but have a promising learning potential in the long run, because other countries could be 'free-riding' on their efforts. In this sense, spillovers appear to have two different connotations. In making learning a public good, they produce a positive effect as technological progress spreads to regions beyond the one that has created it. For the same reason, however, they may threaten proprietary knowledge and hinder the opportunities for the knowledge creators to fully profit from their learning processes. Thus, their presence raises, among others, concerns about intellectual property, strategic 'know-how' and associated competitive advantages, etc.

It becomes important to conceive policy instruments that can deal with both positive and negative aspects of technology spillovers. If one translates the above-described arguments to the international context, they could provide a rationale for forging sound international cooperation on research, development, demonstration and deployment activities (summarised as RD3, following [19]) for those technologies that could contribute to mitigate greenhouse gas emissions. This can also provide an argument to create international partnerships for tapping 'win-win' opportunities, where one party gains access to a broader market for its products, thus being able to benefit from a larger potential for learning-by-doing effects, while the other party gains access to less polluting and more efficient technologies [19].

This brings about the issue of technology transfer, which, as mentioned above, is one of the factors having influence on the magnitude of technology spillovers. In its broader sense, technology transfer encompasses the "diffusion of technologies and technology cooperation across and within countries" [20] and can also be seen as a learning process [21]. Technology transfer, better understood as technology cooperation, could play an important role in stimulating the technological change necessary to achieve a sustainable global energy system in the long term, and specifically, in relation to climate change, an energy system with low release of greenhouse gas emissions to the atmosphere $[20,22]$. In this context, a particularly important dimension is that of technology cooperation between industrialised and developing countries.

\section{The ERIS model}

ERIS is a simplified multi-regional energy-system 'bottom-up' optimisation model that endogenises learning curves [6,7]. The current version includes an electric and a non-electric sector. In the electric sector, electricity generation technologies compete to supply an exogenously given electricity demand. In the non-electric sector, fuel production technologies compete to supply an equally exogenously given non-electric demand, which corresponds to the aggregation of the demand for final-energy fuels other than electricity. Technology representation is relatively detailed. In each region, thirteen electricity generation technologies and twelve non-electric production technologies are considered.

The ERIS model used for this analysis includes eleven world regions. Five regions portray the so-called Annex B group of the Kyoto Protocol: North America, Western Europe, Pacific OECD (including Japan), the former Soviet Union and Eastern Europe. 
Six additional regions represent the non-Annex B group: centrally planned Asia, South East Asia, Other Pacific Asia, Latin America, South-Saharan Africa and the Middle East.

In ERIS, for some technologies in the electric sector, the investment costs follow learning curves (see Figure 1 for the curves assumed in this exercise). For the other technologies, it is assumed that learning rates are zero. That is, their costs remain constant. The learning curves considered here are standard single-factor learning curves, where cumulative installed capacity is used as a proxy for accumulated knowledge and experience. These curves allow capturing the effects of market experience (learning-by-doing) in the progress of specific technologies. The effects of R\&D activities (learning-by-searching), another important channel of technological learning, are not considered.

Figure 1 Learning curves assumed in this analysis. The learning rate (LR) for each technology is indicated in the diagram

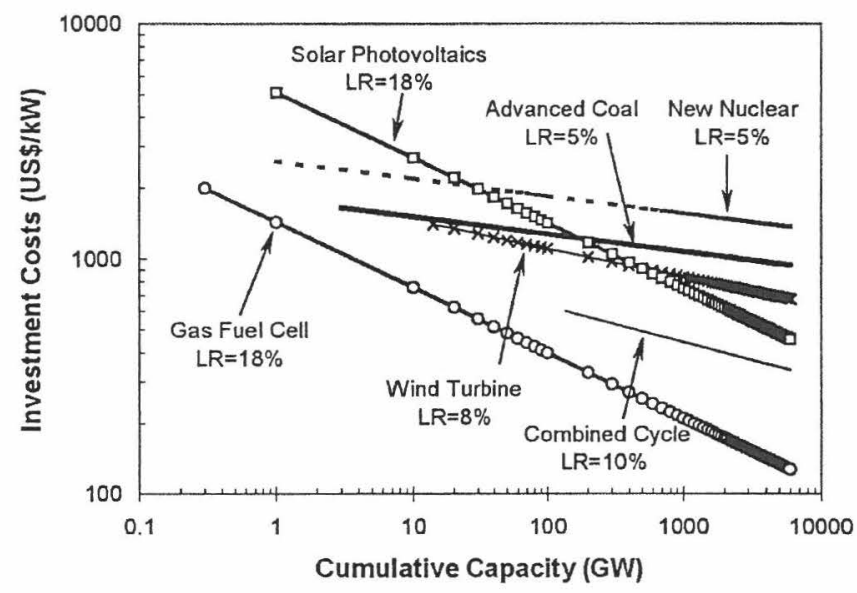

When the original formulation of the learning curves is included in standard linear programming models, the result is a non-linear and non-convex optimisation problem. Such a kind of problems possesses several local optima, and a global optimal solution cannot be guaranteed with standard non-linear optimisation solvers. Thus, here, following the work of [23-25], we resort to a linearisation of the problem applying a piece-wise approximation of the curves through inixed integer programming (MIP) techniques. The MIP approach allows identifying an optimum for the approximated problem, although at a higher computational cost. For a description of the MIP approach used in ERIS see [6].

When models with perfect foresight, such as ERIS, endogenise technological learning, it is cost-effective for the model to make higher, early investments in initially expensive technologies if they exhibit sufficient cost reduction potential along the time horizon. The cost reduction potential depends, among others, on the parameters assigned to the learning curve, the maximum growth rates allowed, the maximum potential for capacity or activity of the different technologies and the spatial scale of the learning process.

This modelling result highlights the fact that, from a long-term perspective, it could be sensible to invest today on the learning process of promising technologies that could 
become competitive in the long run. However, although some learning technologies may appear attractive in a model with perfect foresight, some of them are unlikely to be chosen in a natural way in short-term profit oriented markets, also because of market imperfections. Therefore, policy measures might be needed to support their learning processes, i.e. to cover the 'learning investments'. In this way, the technological learning concept conveys an important policy message regarding energy technology dynamics: sustained efforts in $\mathrm{RD} 3$ activities are required in order to stimulate the cumulative and self-reinforcing processes that drive to progress and diffusion of emerging cleaner energy technologies.

The spatial scale of the learning process has a significant influence on the model outcome. Customarily, models endogenising learning curves assume that the learning process takes place at the global scale (see e.g. $[7,26,27])$. This assumption appears consistent with current globalisation trends and globally active energy-technology manufacturers and energy-services companies, factors that could make a global learning process likely for many technologies. Still, it should not be taken for granted for all technologies. In many cases, a truly global learning process will require substantial and conscious international cooperation efforts in energy-related RD3 activities and sound technology transfer strategies emphasising, among others, local science and technology capacity building that could allow countries to assimilate and adapt experience accumulated somewhere else. In addition, it is possible that a technology could benefit more from learning processes in other technologies or industries, rather than from installations in other regions of the world.

These arguments highlight two important points. First, from the modelling point of view, it appears reasonable to study regional, i.e. sub-global, as well as global learning. Second, from a policy-making point of view, it is important to notice that, in order to achieve a higher degree of technology spillovers in the real world, policy actions may be required.

In the ERIS model, the notion of geographical 'learning domain' is used to define the scale of the learning process. Using this notion, the scale of the learning process can be modified, associating different regions to different learning domains. For a given learning technology, capacities deployed across regions belonging to a given geographical 'learning domain' are added up to obtain an aggregate cumulative capacity, which is used for the computation of the corresponding investment costs. The resulting specific investment cost is common to all the regions associated with a given domain. Thus, deploying the technology in one of these regions results in a cost reduction in all regions belonging to the same 'learning domain'. For example, if the learning is global, capacities across all regions are added up to obtain a global cumulative capacity and a corresponding specific investment cost at the global level is computed.

The scale of the learning process depends on the degree of spillover between different regions, i.e. the degree to which the development and deployment of a particular technology in a given region may influence its cost effectiveness in other regions. For instance, assuming a global scale of learning implies full spillover across all world regions. Therefore, changing the scale of learning implies changing the configuration of spillovers across regions. It must be noticed that the approach outlined here is limited in the possible configurations that can be represented, since it implicitly assumes that between the regions within a given domain, learning spillover is full while between regions belonging to different domains it is zero. 
Thus, it is implicitly assumed that the regions belonging to a given 'learning domain' are able to benefit fully from the learning spillovers. However, as discussed in [3], different countries and regions may have different assimilation capacities, i.e. different abilities to use technology spillovers for their own benefit.

The reader should bear in mind how the learning mechanism operates in the model. Due to the underlying increasing returns (i.e. the more capacity is accumulated the smaller the investment costs become), the model tends to act in an 'all-or-nothing' fashion. If there is enough 'learning potential' for a given technology, it is likely that it will enter at the maximum growth rate allowed. If, on the contrary, the 'learning potential' is not attractive enough, the technology is likely to be 'locked-out' of the system or left only with a marginal contribution.

It should also be clarified how the emission trading mechanism operates in this 'bottom-up' context. Emission trading basically allows the reallocation of the carbon reduction targets and, therefore, of the incentives to deploy low-carbon technologies among the regions participating in the trade system. Also, since expenses and revenues of emission permits are not endogenous to the model but can only be computed ex-post, our cost-minimisation approach cannot directly measure the benefits of trading.

\section{Description of the cases in this analysis}

As illustration of the model dynamics, we consider a baseline scenario without constraints in carbon emissions (referred to as REF case) and a carbon-constrained scenario. The constrained scenario portrays a situation where the Annex B regions must fulfil a 'Kyoto-for-ever' $\mathrm{CO}_{2}$ reduction target. In this illustrative scenario, we assume that the US remains outside the Kyoto Protocol. In the regionalisation of our model, the North America (NAM) region comprises both the US and Canada. Therefore, the NAM region faces a target that is equivalent only to Canada's Kyoto commitment.

Under this carbon-constrained scenario, we distinguish three different cases corresponding to three (emission trade regimes). In the first regime, no emission trading across regions is allowed (this case is labelled as KNT). In the second regime, the Annex $\mathrm{B}$ regions are allowed to trade emissions among them but not with non-Annex $\mathrm{B}$ regions (this case is labelled as KBT). In the third regime, non-Annex B regions join the permits market from 2010 (case labelled as KFT). Non-Annex B regions are not subject to emissions reductions but they cannot exceed their emissions in the unconstrained case. Table 1 summarises the four cases compared here.

Table 1 Summary of the cases examined in this analysis

\begin{tabular}{ll}
\hline Abbreviation & Case \\
\hline REF & Reference unconstrained case \\
KNT & Kyoto-for-ever case without emission trading \\
IBT & Kyoto-for-ever case with trade between Annex B regions \\
KFT & Kyoto-for-ever case with global trade beginning in 2010 \\
\hline
\end{tabular}


For this exercise, both electric and non-electric demands in each world region have been taken from the SRES-B2 scenario developed with the MESSAGE model [28], which is a scenario of gradual developments in population, economic growth and energy requirements. It must be noticed, however, that no attempt is made here to reproduce or emulate the B2 developments reported in [28].

For the sake of clarity, results are reported at an aggregate level for two main groups, namely Annex B and non-Annex B and, where appropriate, at the global level. The time horizon considered for this analysis is 2000-2100 with 10-year time steps. A 5\% discount rate is applied for all calculations.

We illustrate the response of the model under two different spatial scales of learning. The first case is a situation where learning occurs at the global scale. In the second case, a geographical fragmentation of the learning process is assumed, i.e. the spatial learning domain of the technologies is subdivided into Annex B and non-Annex B groups, which learn separately. That is, technologies in the Annex B group cannot benefit from capacity accumulation in the non-annex $B$ group and vice versa.

It is assumed that all technologies exhibit the same spatial scale of learning and that such scale remains unchanged along the time horizon. As an additional simplification, the learning rates remain the same under the different cases. That is, the main effect of moving from a global learning curve to a regional one is that of reducing the learning potential of the technologies, but no changes in the learning rate were considered here. The caveat must be made that the effects of considering regional learning rates could be significant.

Learning spillovers and emissions trading are the two mechanisms that allow interactions between regions in the model. Table 2 summarises which of them provides an interaction between the Annex B and non-Annex B groups in each of the cases examined here.

Table 2 Summary of interactions between the Annex B and non-Annex B groups in the cases examined here

\begin{tabular}{lllll}
\hline & \multicolumn{4}{c}{ Emissions trade regimes } \\
\cline { 2 - 5 } Learning process & $R E F$ & $K N T$ & $K B T$ & $K F T$ \\
\hline Global & Only spillover & Only spillover & Only spillover & Trade and spillover \\
Annex B/non-Annex B & No interaction & No interaction & No interaction & Only trade \\
\hline
\end{tabular}

\section{Illustrative results}

In this section, we will discuss some selected results that illustrate the dynamics of the model. When discussing the technology mix, we will mainly concentrate on the electricity generation sector, where learning technologies have been considered. Carbon dioxide emissions, however, are reported for the whole energy system. The reader should bear in mind that these results are only illustrative and they do not intend to provide insights about the role of particular technologies but mainly to highlight the combined effects of emission trading and spillovers in our model. 
In order to provide an adequate context for our discussion below, we first illustrate the global development for one of the reference cases, namely the case where the technologies are learnt at a global scale. Figure 2 presents the evolution of the global electricity generation for the reference (REF) case, when the scale of learning is global. As can be seen, in this scenario, a substantial transformation of the global generation mix takes place. The role of traditional fossil-fired power plants is substantially reduced, as more advanced technologies such as gas fuel cells, advanced nuclear power plants and a cluster of renewable-based technologies develop and diffuse. Combined-cycle gas turbines play an important bridging role in this transition. In the long term, the market share of renewable sources, fuel cells and nuclear technologies increases.

Figure 2 World electricity generation in the reference case with a global learning scale. The abbreviations for the technologies are as follows: HCC: Conventional Coal, HCA: Advanced Coal, OLC: Oil Conventional, GCC: Gas Combined-Cycle, GSC: Gas Steam Cycle, GTR: Gas Turbine, GFC: Gas Fuel Cell, BIP: Biomass Power Plant, NUC: Nuclear Conventional, NNU: New Nuclear, HYD: Hydro, STH: Solar Thermal, SPV: Solar PV, WND: Wind Turbine

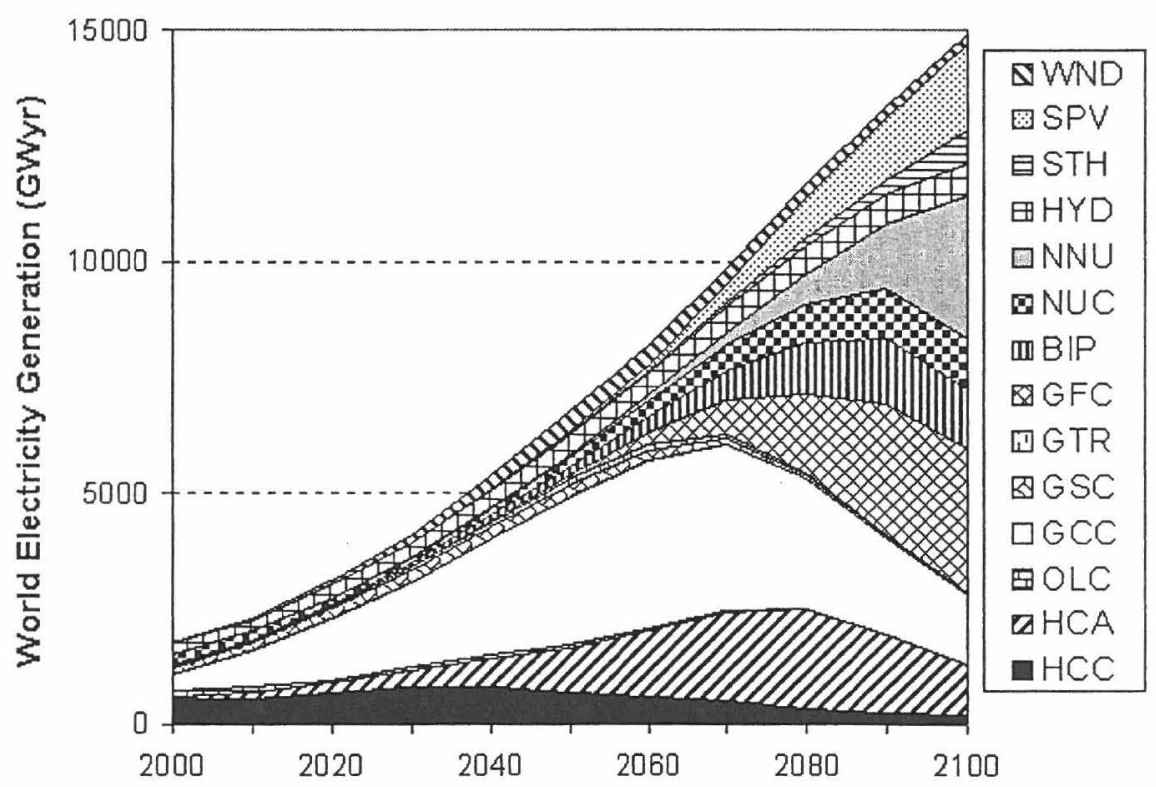

Figure 3 presents the global carbon dioxide emissions for this reference case. Global emissions rise steadily for the most part of our time horizon, reaching a peak of about 18.8 Gtons of carbon around 2070 and beginning to decrease afterwards. Emissions from the Annex B group rise in the medium term but begin to decline in the second half of the 21 st century. Emissions from the non-Annex B regions experience a substantial increment making this group the main contributor to global emissions in the long term. A decline becomes evident only in the last few decades of the 21 st century. 
Figure 3 World carbon dioxide emissions in the reference case when the scale of learning is global. Emissions from the Annex B and non-annex B groups are distinguished

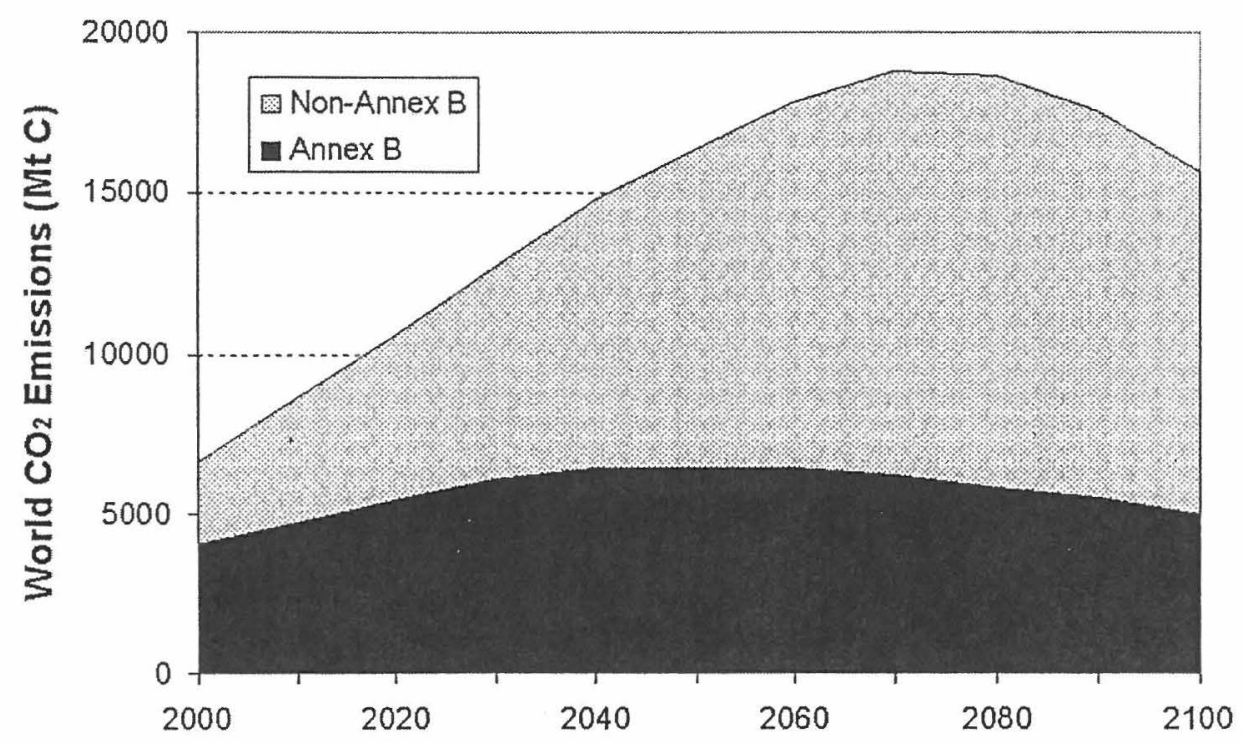

Changing the scale of the learning process alters the ranking of the different technologies in the individual regions and, therefore, the resulting technology mix in the model. As an illustration of this effect, Figure 4 presents the electricity generation mix in the years 2050 and 2100 for the Annex B and the non-Annex B groups in the reference case for both the global and Annex B/non-Annex B scales of learning.

Figure 4 shows that with global learning, technologies like solar photovoltaics and advanced coal plants are introduced in the Annex B regions, while with Annex B/ non-Annex B learning they remain 'locked-out'. Some, less pronounced differences in the generation mix of the non-annex B group are also observed.

The magnitude of the changes depends on a number of factors. However, when comparing both groups of regions, it becomes evident that changes are more significant in the Annex B group. This is due to the fact that some of the learning technologies have a larger learning potential in non-Annex B regions than those in Annex B regions. Among others, potential for some renewable resources is higher in non-Annex B regions and electricity demand grows at a much faster pace there. Therefore, when the learning process takes place in two separated domains, namely the Annex B and non-Annex B groups, in the Annex B group these technologies cannot achieve enough cost reductions as to become cost effective and their market share decreases as compared to the global learning case. On the other hand, the learning potential available within the non-Annex B group is still sufficient for some of those technologies such as advanced coal power plants and solar PV to become cost effective and be introduced into the solution. Thus, the variations in their market share in the non-Annex B group in comparison to the global learning case are smaller. 
Figure 4 Comparison of the electricity generation in Annex B and non-annex B groups in the years 2050 and 2100 for the reference case with two scales of the learning process: global and separate Annex B/non-Annex B. The abbreviations for the technologies are as follows: HCC: Conventional Coal, HCA: Advanced Coal, OLC: Oil Conventional, GCC: Gas Combined-Cycle, GSC: Gas Steam Cycle, GTR: Gas Turbine, GFC: Gas Fuel Cell, BIP: Biomass Power Plant, NUC: Nuclear Conventional, NNU: New Nuclear, HYD: Hydro, STH: Solar Thermal, SPV: Solar PV, WND: Wind Turbine
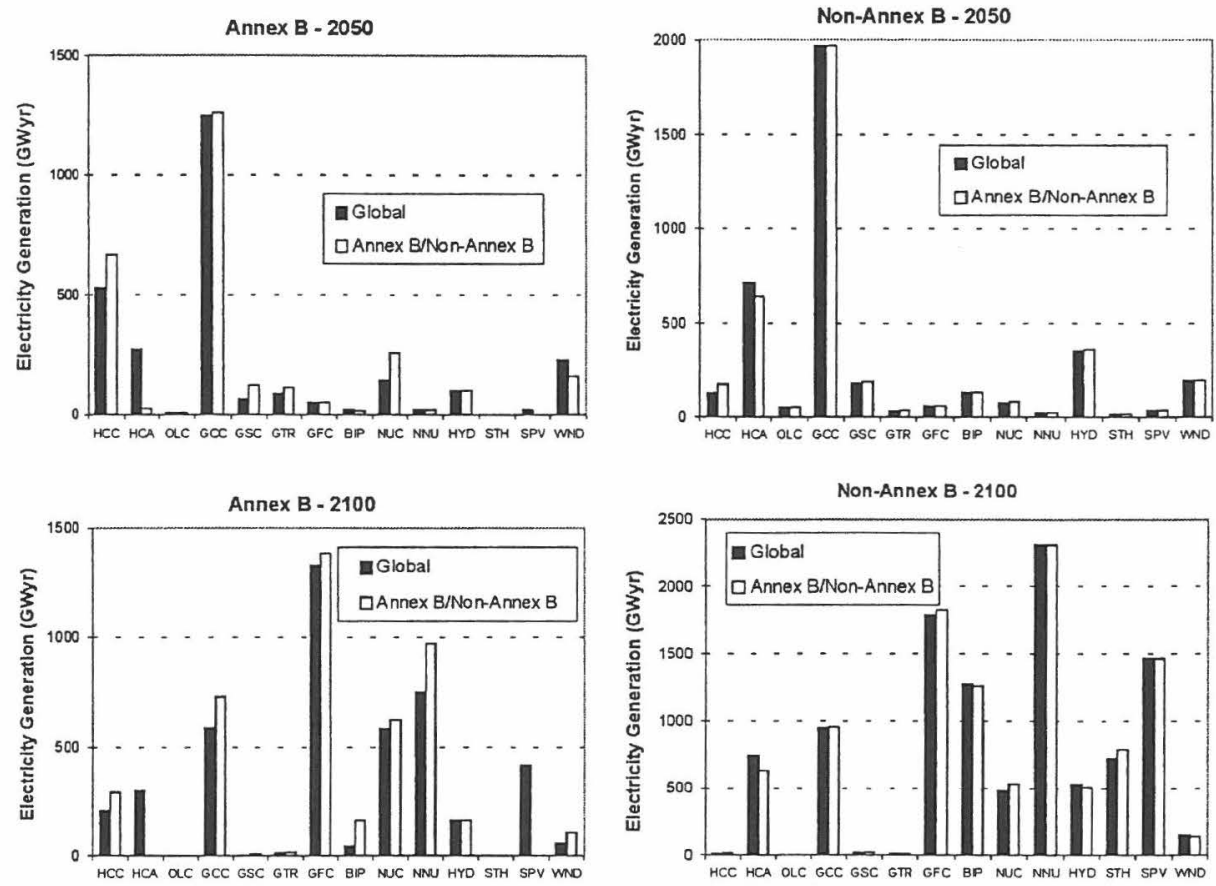

For instance, for a technology like solar photovoltaic cells, initially expensive but with a promising learning rate, not having the possibility of benefiting from the learning potential in non-Annex B regions, means that it remains 'locked-out' of the electricity generation mix of the Annex B group. However, its output barely changes in the non-Annex B group. This example will be examined in more detail below.

One should question, however, how this process could evolve in reality. Although in the model this particular technology still remains attractive in non-Annex B regions, in practice, however, the lack of spillovers could hinder the diffusion of a given technology also there, particularly if these regions depend on foreign direct investment or technology transfer from the Annex B countries to gain access to technologies and associated knowledge. Given the fact that the Annex B countries or companies possess a considerable amount of technology know-how, without the possibility of spillovers, some of the emerging, cleaner technologies would probably not be able to successfully diffuse in the developing regions, which would then continue to use more polluting and less efficient alternatives. 


\subsection{Emission paths in Annex $B$ and non-Annex $B$ groups}

When the Kyoto-for-ever target is imposed on the Annex B regions, the changes in technology mix and emission patterns of the different regions will depend on the possibility of having emission trading, its geographical scope and timing and the possibility of benefiting from spillovers of learning. Figure 5 presents the electricity generation mix in Annex B and Non-annex B groups for the year 2100 in the Kyoto-like constrained cases. As can be seen, with an Annex B/non-Annex B scale of learning, the technology mix in the non-annex B countries does not differ from the baseline unless trading of emission permits with the Annex $\mathrm{B}$ group is possible.

Figure 5 Electricity generation in Annex B and non-Annex B groups in the year 2100 for the Kyoto-for-ever cases considered here (KNT, KBT, KFT) with two scales of the learning process: global and separate Annex B/non-Annex B. The abbreviations for the technologies are as follows: HCC: Conventional Coal, HCA: Advanced Coal, OLC: Oil Conventional, GCC: Gas Combined-Cycle, GSC: Gas Steam Cycle, GTR: Gas Turbine, GFC: Gas Fuel Cell, BIP: Biomass Power Plant, NUC: Nuclear Conventional, NNU:

New Nuclear, HYD: Hydro, STH: Solar Thermal, SPV: Solar PV, WND: Wind Turbine
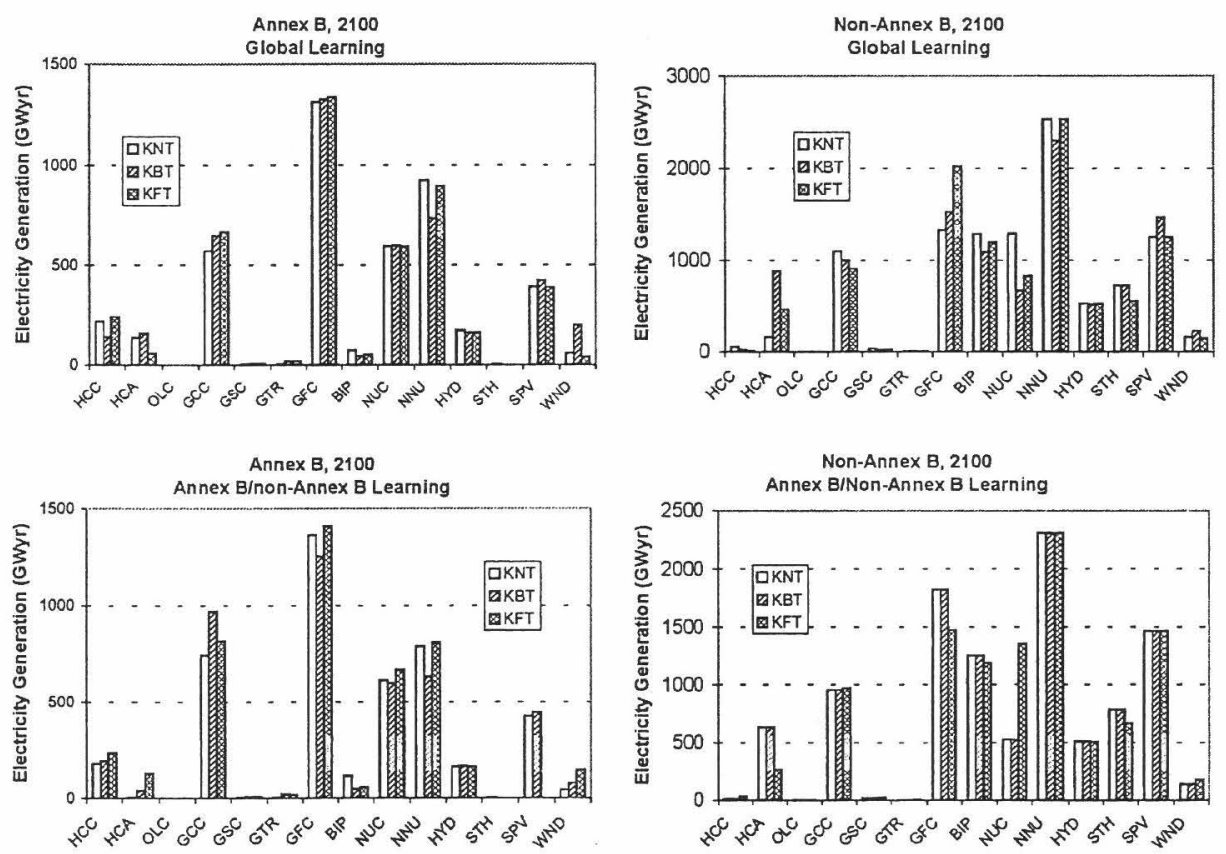

Figures 6 and 7 present the emission paths for the Annex B and the non-Annex B groups, respectively, for the different cases considered here under both global and Annex B/ non-Annex $B$ scales of the learning process.

The emission paths of the Annex B group when the carbon constraint is imposed (Figure 6) are similar for both scales of learning. The lowest Annex B emissions correspond to the situation where there is no possibility for trading emission rights neither between Annex B regions nor with non-Annex B regions (KNT case). The reason is that in the KNT case, the Annex B regions are forced to achieve the emission reduction 
by themselves and have no access to cheaper mitigation options somewhere else or to 'hot air'. Allowing emissions trading within Annex B regions (KBT case) relieves to some extent the pressure on these regions to undertake intra-region abatement, in particular, because Annex B regions have access to 'hot air' from the former Soviet Union. Consequently, $\mathrm{CO}_{2}$ emissions are higher in the Annex $\mathrm{B}$ regions than those in the KNT case. Finally, when global trade of emission permits is possible (KFT case), the Annex B group has access to cheaper mitigation options in the non-Annex B group and, consequently, its emissions become higher.

Figure 6 Emission paths in the Annex B group for the different cases under consideration here (REF, KNT, KBT and KFT) and the two scales of the learning process (global and Annex B/non-Annex B). Notice that the scale on the vertical axis does not start in zero

Annex B, Global Learning

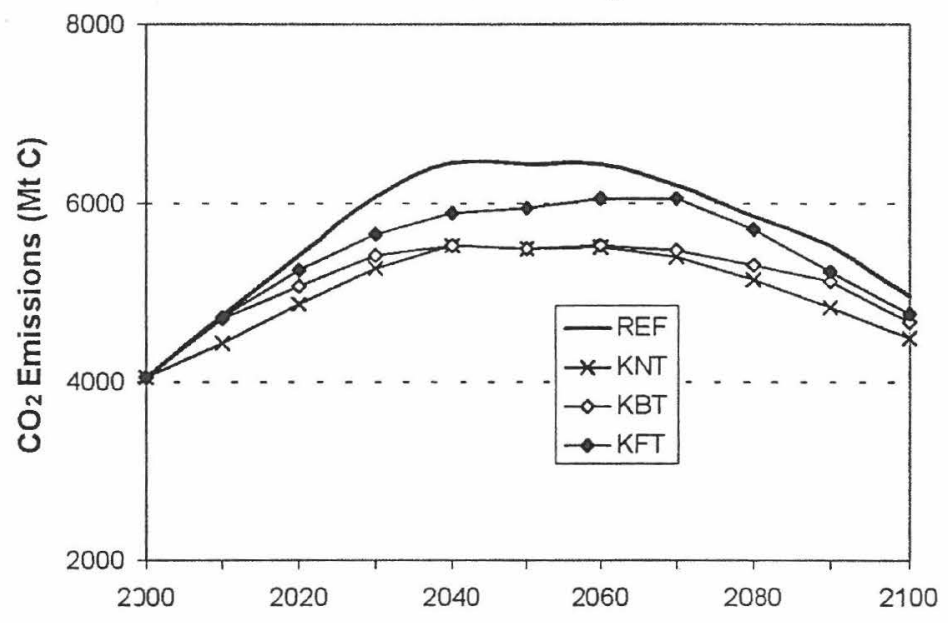

Annex B, Annex B/Non-Annex B Learning

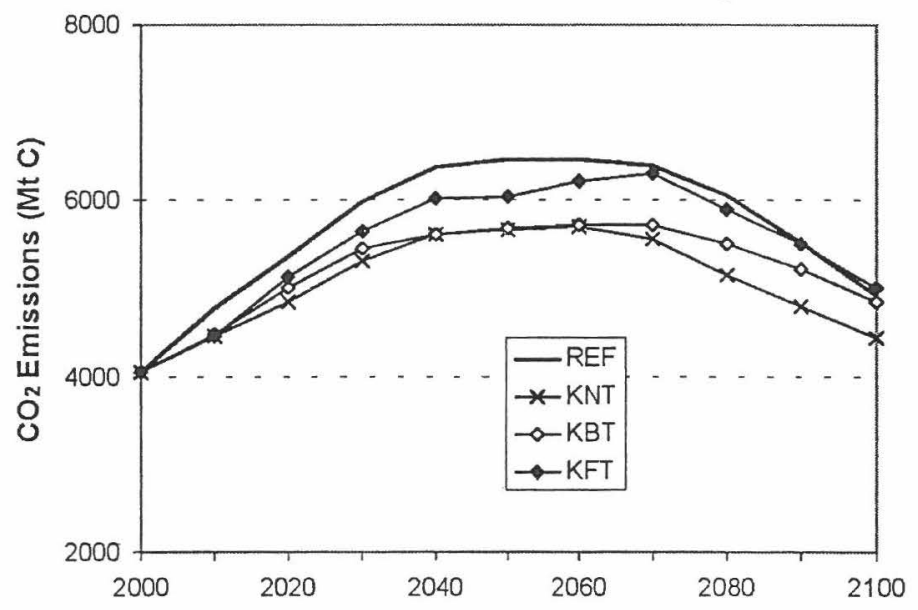


Figure $7 \mathrm{CO}_{2}$ emissions in the non-Annex $\mathrm{B}$ group for the different cases under consideration here (REF, KNT, KBT and KFT) and the two scales of the learning process (global and Annex B/non-Annex B). Notice that the scale on the vertical axis does not start in zero

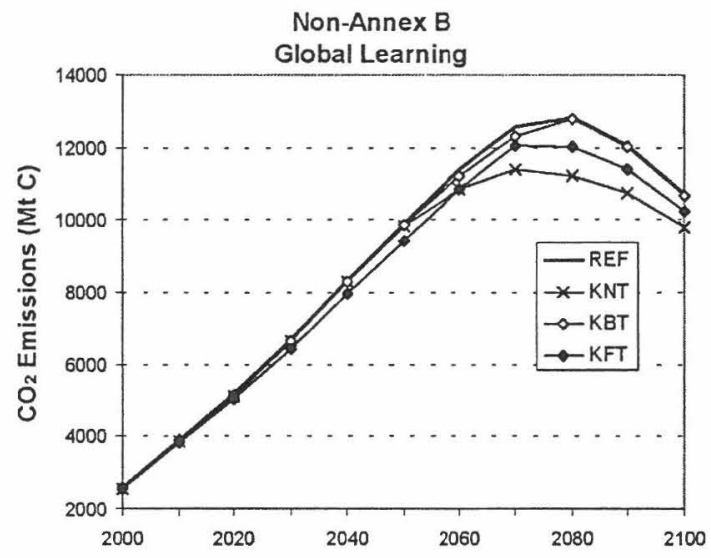

Non-Annex B Annex B/Non-Annex B Learning

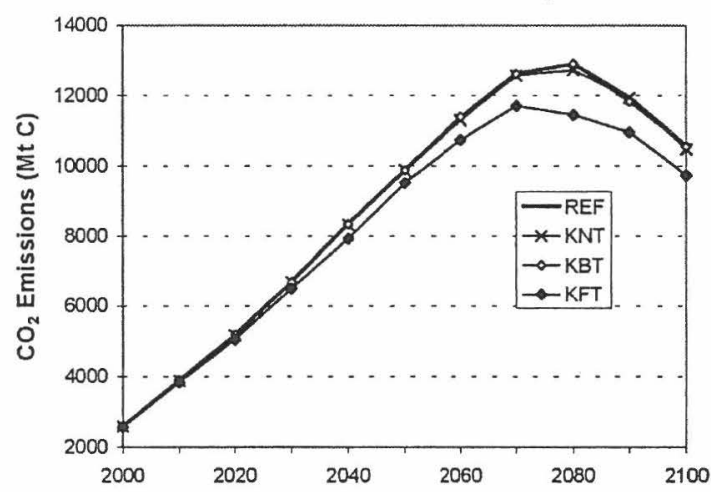

On the other hand, emission paths in the non-Annex B group (Figure 7 above) differ for both scales of learning. When the learning takes place at the Annex B/non-Annex B scale, non-Annex B emissions in the KNT and KBT cases remain the same as in the reference $(\mathrm{REF})$ case. Clearly, without interaction between the two groups of regions, actions in the Annex B group have no effect on the technology deployment of non-Annex $\mathrm{B}$ regions. Once global emission trading becomes possible (KFT case), emissions in the non-Annex $\mathrm{B}$ group fall below the baseline, as these regions sell emission permits to the Annex B regions.

If the learning takes place at the global scale, however, the behaviour is different. In this situation, learning spillovers provide a mechanism of interaction between the two groups. Therefore, even without the possibility of trading emission rights, mitigation actions in the Annex B group will affect the technology mix of the non-Annex B group.

In particular, non-Annex $B$ emissions are significantly reduced from the baseline in the KNT case. As a consequence of significant abatement actions in the Annex B group, the learning process of low-carbon technologies is stimulated (through deployment). 
With global spillovers, these technologies become more attractive in non-Annex $B$ regions as well. Consequently, carbon emissions in non-Annex B decrease. This situation will be analysed in some more detail below.

With trade in Annex B (KBT case), the pressure on Annex B regions to reduce emissions decreases, in particular, in the first periods when they have access to the 'hot air' bubble. Thus, the incentive to stimulate the installation of learning, low-carbon technologies is reduced in the Annex B group. This is reflected, through spillovers, in the non-Annex B group. As a consequence, carbon emissions in the non-Annex B group increase in comparison to the KNT case and reach almost the levels of the REF case.

In the KFT case, emissions in the non-Annex B group are reduced below those in the REF and KBT cases, but are still above those in the KNT case. Since the non-Annex B regions can participate in the trade, they have an incentive to reduce emissions below their baseline, in order to sell emission rights. Thus, they have an incentive to stimulate the learning process of low-carbon technologies. However, at the same time, permit-buying regions in the Annex B group experience the contrary situation. With the possibility of buying permits from the non-Annex B group, their incentive to deploy low-carbon technologies reduces.

The final outcome depends, among other things, on the relative weight of these two effects and on the emission target. In this particular case, where the Kyoto-for-ever target is relatively weak in relation to the global emissions in the baseline, the incentives to deploy expensive very low or zero-carbon technologies in the non-Annex B are not high, since the target can be fulfilled with less expensive, medium-carbon technologies such as gas-fired combined-cycle turbines. Therefore, although emissions are reduced compared to the baseline, they do not reach the levels of the KNT case, where the pressure on Annex B regions to reduce emissions through intra-region mitigation measures was much harder.

A closer look at the emission profiles of Annex B and non-Annex B regions in the KNT case for both the global and the Annex B/non-Annex B learning scales is instructive (see Figure 7 above). As mentioned before, in both cases Annex B regions are forced to fulfil the emission reduction target through 'in-house' measures and the emission paths of the Annex B group under both learning scales do not differ much from each other. However, the emission profiles of the non-Annex B group are very different.

In the global learning case, the non-Annex B group reduces emissions as compared to the baseline, despite the fact that these regions are neither facing an emission reduction target, nor have the possibility of participating in the emission trading system. The effect, thus, is due to the presence of global spillover of learning. Annex B regions have to deploy low-carbon technologies in order to curb their carbon emissions, and such deployment actions drive to cost reductions, which, through spillovers, are shared by the non-Annex $B$ regions. As those technologies become more attractive also in non-Annex $\mathrm{B}$ regions and are deployed, non-Annex $\mathrm{B}$ emissions are reduced. This is an example of how the model with learning spillovers can capture the possible effects that climate policies in a given region may have in the technologies deployed in others.

On the contrary, when spillover of learning is not possible between the Annex B and non-Annex B groups (Annex B/non-Annex B learning case), the emissions of the non-Annex $B$ group barely differ from the baseline. In this condition, those regions cannot profit from the cost reductions of low-carbon technologies triggered by abatement actions of the Annex B group. In addition, under a no-trade situation, they have no incentive to reduce emissions in order to sell emission rights. The KNT case with 
Annex B/non-Annex B learning scale represents a situation where the actions between the two groups of countries are fully 'decoupled'.

Clearly, in a real, more and more interconnected world, it is not possible to have a direct parallel to the hypothetical Annex B/non-Annex B learning case described here. Climate and/or technology policy actions in Annex B regions are bound to have some effects on technologies deployed in non-Annex B regions. However, this modelling result is still insightful, as it illustrates the possible effects of non-cooperative strategies both in climate change and technology policies at the international level.

To summarise, Figure 8 presents the global energy-related carbon dioxide emissions for the different cases and the two learning scales examined here. As explained above, under a global scale of learning the highest emission reduction is achieved in the KNT case, mainly due to the effects of learning spillovers towards the non-Annex B regions, triggered by the significant abatement actions in individual Annex B regions, which are not allowed to trade permits between them or with the Annex B regions. With an Annex B/non-Annex B scale of learning, and therefore no possibility for learning spillovers between Annex B and non-Annex B, the most significant emission reduction occurs in the KFT case, where the scope of emissions trading is global and non-annex B regions reduce emissions below their baselines in order to sell permits to the Annex $B$ regions.

Figure 8 Global $\mathrm{CO}_{2}$ emissions for the different cases (REF, KNT, KBT and KFT) and the two scales of the learning process (global and Annex B/non-Annex B) under consideration here
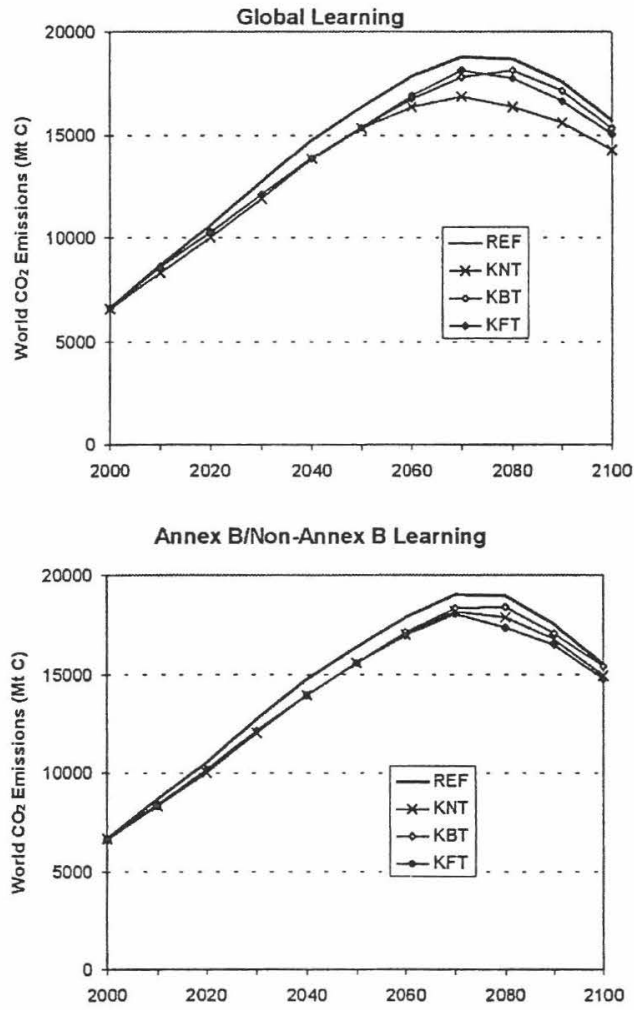
As for the effects of the learning scale on the global emissions in the different cases, emissions in the global learning cases are somewhat below those in the Annex B/ non-Annex B cases, thus pointing out to a positive effect of global spillovers. However, with a weak Kyoto-for-ever target, the differences are not substantial, with the exception of the KNT case as described above.

Finally, Figure 9 presents the mitigation costs for the different cases. They are computed as the difference between the total discounted system costs of the reference case and those of the carbon-constrained cases with different modalities of emission trading. The benefits of allowing emission trading and of extending its scope to the non-Annex B regions are evident. Also, mitigation costs are somewhat lower for the global learning spillovers case compared to those in the Annex B/non-Annex B case.

Figure 9 Mitigation costs for the different modalities of emissions trading (KNT: No Trade, KBT: Trade in Annex B, KFT: Full Trade) and the two learning scales, i.e. global and Annex B/non-Annex B

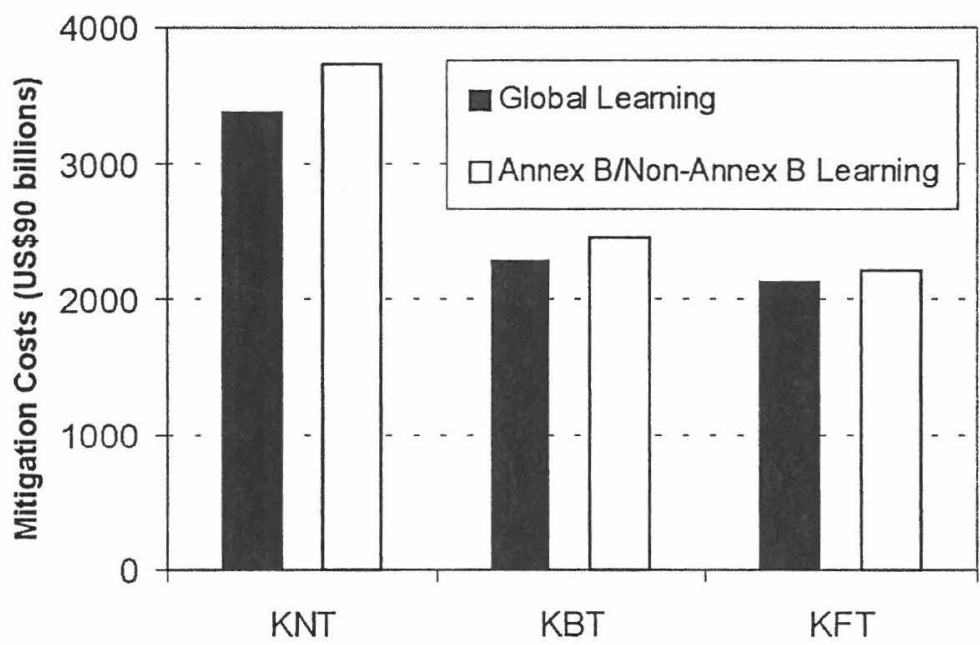

\subsection{Deployment of solar photovoltaics}

We will illustrate how the variation of the scale of learning affects the deployment of technologies using the case of solar photovoltaic (PV) cells as an example. We have chosen solar PV for the sole reason that it represents an adequate illustrative case, but the considerations exposed here also apply to other learning technologies.

Solar PV has undergone significant improvements, constituting already a sound option for off-grid remote and special applications [29]. However, it still has a long way to go to become a widespread energy technology and many hurdles have to be surmounted. Although appreciable cost reductions have occurred in the last few decades, the technology is still in the early part of its learning curve and it is currently too expensive for utility grid applications. Nonetheless, there appears to be ample room for efficiency and cost improvements [30].

In order to ensure a sustained growth of current markets and the entrance to broader ones, a number of factors must be addressed. Of course, major cost cuts and efficiency improvements are still necessary to enable competitiveness. Thus, development of 
materials, which allow lower cost manufacturing with higher conversion efficiency, is a critical success factor [31]. Also, as availability of raw materials may become an issue for large-scale production, PV technologies using lower amounts of cheaper materials may be favoured. In addition, reductions must be achieved not only in the module costs but also in the Balance of Plant, particularly in area-related costs. In such a perspective, although the current market is still dominated by the standard crystalline silicon cells, thin-film cells, enabling to reduce material costs and collecting area, provide an attractive alternative and are expected to play an increasing role in the future PV market [32].

Besides technical aspects, other issues are also relevant for its future competitiveness. Among them, the standardisation of components, materials and designs should be addressed [31]. Also, new business strategies, emphasising the sales of complete service solutions, instead of a technology, and alliances between manufacturers must be explored and an adequate infrastructure for finance, distribution, installation and support developed.

The importance of developing new strategies to stimulate the interest of potential adopters in solar PV is well recognised. Kaplan [33], for instance, has stressed the need to consider specific schemes for groups beyond the so-called early adopters, arguing that the decision-making process of early and later potential adopters is different and thus requires different stimuli. While early adopters, being more risk-taking, may rely on available technical and economical information to make a decision, for other groups of adopters the sole availability of such technical knowledge may not be sufficient to make a favourable decision. Thus, an approach based on allowing them to become 'familiar' with the technology by promoting trial and error and learning through experience, for instance with small experimental projects, could be more effective than a conventional commercialisation process.

Figure 10 presents the electricity produced by this technology under the different cases and scales of learning in the years 2050 and 2100 for both the Annex B and non-Annex B groups. The discussion here will be made with reference to the mentioned figure. Notice that under the particular assumptions made here regarding learning parameters, maximum growth rates, potential etc, solar PV already penetrates to a significant extent in the reference case.

We do not intend to argue that this constitutes a 'realistic' case, but this is one that reflects well the typical behaviour of model that endogenises technological learning. That is, and as mentioned above, under the action of the self-reinforcing learning mechanism, the model tends to act in an 'all-or-nothing' fashion. Thus, when solar PV becomes attractive in the reference case, the model tends to install it to the maximum extent possible. Although other factors also intervene, in the results presented here, the 'all-or-nothing' characteristic drives to comparable penetration of this learning technology across the different cases where it becomes attractive.

We will first discuss the deployment of the technology in the Annex B group (left side of Figure 10). As mentioned above, under the reference scenario solar PV penetrates in the Annex B group only if the learning takes place at the global scale. When the scale of learning is reduced to the Annex B domain, the technology remains 'locked out' there. In the carbon-constrained scenario, and still under the global scale of learning, the technology continues to play an important role. Variations between the cases with and without emission trading exist but they are small. 
Figure 10 Electricity output of solar photovoltaics in the Annex B and non-annex B groups in the different cases (REF, KNT, KBT and KFT) and scales of learning (global, Annex

$\mathrm{B} /$ non-Annex B) for the years 2050 and 2100
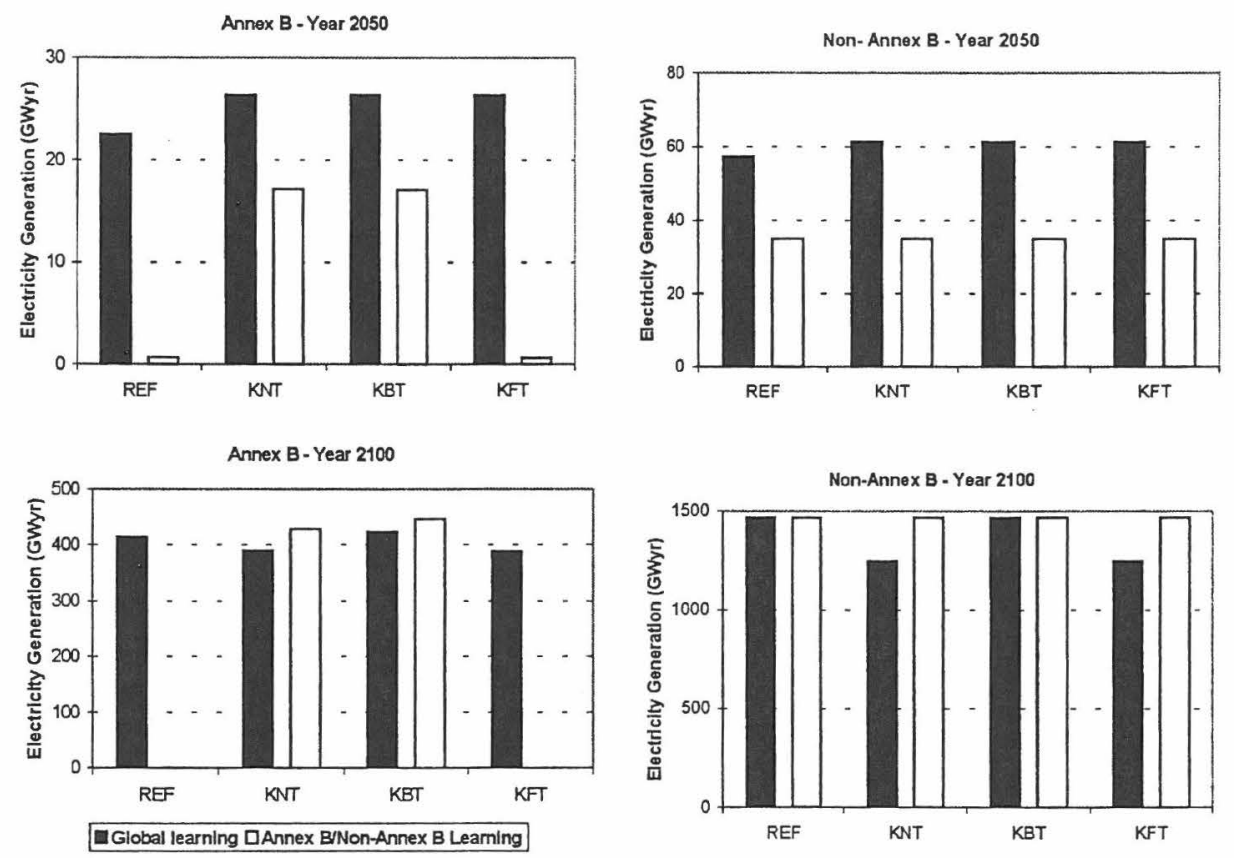

If the learning takes place at the Annex B/non-Annex B level, however, the emission trading scheme affects solar PV's deployment in the Annex B group significantly. When no trade is possible across regions (KNT case), Annex B regions are forced to meet their respective targets with domestic measures. In these conditions, they necessarily introduce low-carbon technologies. Solar PV is one of them and becomes cost effective under these circumstances, despite the fact that learning takes place at a more reduced scale.

This is still the case when trade of emission rights within the Annex B group is allowed (KBT case). Annex B regions have access to 'hot air' from the former Soviet Union in the short term but, in the long run, permit-selling regions within the Annex B group still have to stimulate the penetration of low-carbon technologies, although to a much lower extent than those in the KNT case. Solar PV is one of them and continues to grow at the maximum possible rate. However, with the allowance of trade across all world regions (KFT case), cheaper mitigation options from the non-Annex B regions become available and the technology is 'locked-out' from the Annex B group.

We now turn to the penetration of this technology in the non-Annex B group (right side of Figure 10). Under a global scale of learning, the technology is cost-effective already in the reference scenario. It remains attractive under the different cases of the carbon-constrained one, although some fluctuations in its output are observed.

Under the Annex B/non-Annex B scale of learning, the technology is, as mentioned above, also introduced already in the reference scenario. When the carbon constraint is imposed on Annex B regions, the output of solar PV remains unchanged for all three cases. In the KNT and KBT cases, given that no emission trading between Annex B and non-Annex $B$ regions is allowed and without spillovers of learning between the two 
groups, there is no possibility for interaction. Thus, actions in the Annex B group do not affect the technology mix in the non-Annex B group. In the KFT case, the non-Annex B regions have an incentive to deploy low-carbon technologies in order to sell emission rights to the Annex B group. Solar PV remains cost effective and its output does not change as compared with the other cases. Without spillovers of learning, however, these installations cannot affect the cost effectiveness of the technology in the Annex B group, where as discussed above, the technology is 'locked out'.

The solar PV's case illustrates how, in this perfect-foresight model, the presence or absence of learning spillovers, the scope of the emission trading mechanism and the strictness of the carbon constraint are determining factors in the successful penetration of a given technology.

In reality, however, markets or policy makers most likely would not behave as suggested by the model and completely 'lock out' these technologies. However, the risks that the lack of technology cooperation between Annex B and non-Annex B regions, represented here by the absence of learning spillovers, may imply for the diffusion of clean energy technologies at the global level can still be significant.

But, since the 'all-or-nothing' behaviour of the model does not adequately reflect real situations, efforts should be devoted to improve the model representation. An important aspect is dealing with the effects of uncertainty. Huge uncertainties exist in economic, technological, social and natural systems, and decision makers need to make technology choices that help them to increase their flexibility to deal with changing market, environmental, regulatory, political, etc. conditions.

Uncertainty is, together with learning, one of the core mechanisms of technological change $[26,34]$. Technological change can be seen as an evolutionary cumulative learning process building upon accumulation of knowledge and experience. Deliberate and sustained efforts are required in order to stimulate the acquisition of relevant experience and the preservation of the knowledge associated with a given technology, which allow achieving cost and performance improvements, vital factors for its survival in the marketplace.

The learning, or experience, curve appears as a useful model to represent the aggregate effects of such an evolutionary progress. However, many technical, economic, environmental and social factors influence the magnitude of learning rates. Moreover, even if accurate estimates of historical learning curves are available, they cannot be extrapolated into the future. Thus, the future evolution of technology learning processes is uncertain. Therefore, conceiving methodologies to deal with uncertainty, both in learning parameters and in other factors, is an important future task $[26,34]$.

\section{Conclusions}

In this paper, some illustrative analyses have been conducted regarding the effect of emission trading on technology diffusion. Specifically, the role of learning-by-doing spillovers is highlighted as one of the factors likely to have an influence on the action of emission trading. The analysis has been carried out with ERIS, a 'bottom-up' energy-system optimisation model. We examine the effects of different configurations of interregional spillovers of learning in ERIS and the impact of the emission trading mechanism under those different circumstances. 
The representation of multi-regional learning spillovers in the ERIS model helps in capturing the effects that the deployment of technologies in a given region has for the technology choice in other regions of the world. Particularly interesting is the possibility that climate change policies in a region can induce technological progress (here represented as cost reductions) and the diffusion of low-carbon technologies in other regions of the world.

Learning spillovers and emission trading are two mechanisms that allow interaction between different regions in the model. Their presence or absence and their geographical scope and timing will determine whether actions in a given region have an influence in the technology deployment in others or not.

Our major finding is that assumptions on the spatial scale of technology spillovers can have significant implications for the resulting technology mix of different regions and the associated emission profiles and, therefore, for the possible impact of carbon trading on the diffusion of specific technologies. This is especially the case for high-cost carbon free technologies.

The treatment of both technology spillovers and emission trading in this context is stylised. We did not attempt a comprehensive modelling of all the very complex aspects of technological change that may be relevant when conducting an evaluation of the effects of climate policy mechanisms on the energy system. Moreover, endogenised learning curves are considered only for one specific performance indicator of energy technologies, namely their investment costs. Neither did we provide a sophisticated treatment of emissions trading, quantify the potential benefits of the scheme or examine its effects outside the energy-system context. While we recognise that those aspects are necessary to fully evaluate the interaction between emission trading and technological change, their treatment lies outside of our scope. Thus, the results only illustrate the dynamics of the intervening mechanisms in the context of the ERIS model.

While the typical learning curves applied here use costs as performance indicator, learning effects can also be observed in many other characteristics of energy technologies, conversion efficiency among others. While we recognise that their inclusion in the models could be important for a more accurate representation, we do not expect that it would alter the basic conclusions arrived at here. Moreover, it must be noticed that empirical estimates of learning rates for conversion efficiency are normally not available in the literature, thus making additional assumptions necessary. Also, handling learning curves for additional indicators would lead to an increased computational burden.

The role of technology spillovers depends on the framework where they are applied. In the 'bottom-up' context used here, where individual technologies are explicitly included in the model, the presence or absence of spillovers alters the possibilities of a given technology for tapping its learning potential and, therefore, modifies the ranking of the different technologies in a specific region. Consequently, changes in the technology mix and associated emission profiles may be observed.

Other approaches to represent the effects of technology spillovers have been reported in the literature. Grubb et al. [5], for instance, treat international spillovers as an aggregate coefficient that directly affects the emission intensity of the different regions. When examining the role of technology spillovers in relation to climate policies, and the insights provided by different models, it is important to compare the differences in their representation. 
Including learning-by-doing spillovers has also implications for the concept of 'leakage', commonly discussed in climate policy analyses [4,5]. The traditional notion is that leakage is negative, referring to the situation where emission mitigation policies in a given region result in higher emissions in other regions due to, for instance, the relocation of carbon-intensive industries. Typically energy-economic models represent this kind of effects. When learning spillovers are present, the possibility of a 'positive' leakage effect can be considered, where non-committed regions benefit from the adoption of cleaner technologies in regions with emission reduction targets. Some have even suggested that such positive effects could offset the negative effects [5]. We are not confirming or rejecting such proposition here. Our model, limited to a simplified representation of the energy system, does not allow considering negative leakage. However, it seems worth quantifying both effects in a common context to evaluate their relative weight.

In the analysis undertaken here, it was assumed that spillovers across different world regions are either full or non-existent. In reality, spillovers would most likely lie somewhere in between these two extreme values. Their quantification, however, may be difficult. Given the uncertainties regarding the magnitude and nature of international technology spillovers, it is important, on the one hand, to conduct modelling exercises with different sets of spillover coefficients and to develop criteria for their choice in the models. On the other hand, work must be devoted to their estimation out of empirical data for energy technologies.

An additional aspect is of interest here. A 'monolithic-actor' type of optimisation is performed in ERIS, which finds the least-cost energy-system configuration for the whole set of regions. That is, no strategic interactions between regions are modelled here. Under such conditions, higher levels of learning spillovers across regions may be desirable, because a given region can benefit from the cost reductions caused by accumulation of capacity (experience) in other region. Thus, in this kind of model, the presence of spatial spillovers will not imply a disincentive for a given region to undertake the 'up-front' investments that will make a technology competitive, despite the fact that other regions will benefit from those efforts.

In practice, however, this can be an issue of concern. Spillovers appear to have two different connotations. In making learning a public good, they produce a positive effect as technological progress spreads to regions beyond the one that has created it. For the same reason, however, they threaten proprietary knowledge and hinder the opportunities for the knowledge creators to fully profit from their learning processes. Thus, the development of policy instruments capable of stimulating the positive aspects of learning spillovers while reducing the impact of the negative ones is necessary.

The modelling exercise also provides some valuable policy insights. In particular, it highlights the opportunities that international partnerships may create for the diffusion of emerging technologies. Cooperation among industrialised countries and between these and developing countries in research, development, demonstration and deployment (RD3) of more efficient and cleaner energy technologies may foster international learning processes that will contribute to boost their competitiveness in the global energy markets, thus accelerating their penetration and offering long-term environmental and economic benefits [19]. Stimulation of international learning, however, must be balanced against, and made compatible to local requirements for a diversified technological choice according to specific needs and available natural, technological, economic and human resources. Also, as part of the efforts, and in particular to what concerns developing 
countries, sound technology transfer strategies with emphasis in building local capabilities must be outlined [21].

In a world with global energy markets and global environmental concerns, fostering multi-regional technological learning partnerships arises as an important policy intervention mechanism whose effects on the evolution of the energy systems should be investigated. These and other issues related to the effects of learning spillovers and their policy implications should be analysed further.

\section{Acknowledgements}

Financial support from METI (Ministry of Economy, Trade and Industry) and CRIEPI (Central Research Institute of the Electric Power Industry) in Japan for this study is gratefully acknowledged. This paper reports on work of the International Institute for Applied Systems Analysis. Views or opinions expressed in this report do not necessarily represent those of the institute, its National Member Organisations, or other organisations sponsoring the work. The comments of two anonymous referees are greatly appreciated. Any remaining errors are solely the responsibility of the authors.

\section{References and Notes}

1 Chua, S. (1999) 'Economic growth, liberalization, and the environment: a review of the economic evidence', Annu. Rev. Energy Environ., Vol. 24, pp.391-430.

2 Irwin, D. and Klenow, P. (1994) 'Learning-by-doing spillovers in the semiconductor industry', Journal of Political Economy, Vol. 102, pp.1200-1227.

3 Watanabe, C., Zhu, B., Griffy-Brown, C. and Asgari, B. (2001) 'Global technology spillover and its impact on industry's R\&D strategies', Technovation, Vol. 21, pp.281-291.

4 Grubb, M., Koehler, J. and Anderson, D. (2002a) 'Induced technical change in energy and environmental modeling: analytic approaches and policy implications', Annu. Rev. Energy Environ., Vol. 27, pp.271-308.

5 Grubb, M., Hope, C. and Fouquet, R. (2002b) 'Climate implications of the Kyoto protocol: the contribution of international spillover', Climatic Change, Vol. 54, pp.11-28.

6 Kypreos, S., Barreto, L., Capros, P. and Messner, S. (2000) 'ERIS: a model prototype with endogenous technological change', Int. J. Global Energy Issues, Vol. 14, Nos.1-4, pp.374-397.

7 Barreto, L. and Kypreos, S. (2000) 'A post-Kyoto analysis with the ERIS model prototype', Int. J. Global Energy Issues, Vol. 14, Nos. 1-4, pp.262-280.

8 Marchetti, C. (1980) 'Society as a learning system: discovery, invention, and innovation cycles revisited', Technological Forecasting and Social Change, Vol. 18, pp.267-282.

9 Nakicenovic, N. (1997) Technological Change as a Learning Process. IIASA Induced Technology Workshop, International Institute for Applied Systems Analysis, Laxenburg, Austria.

10 Argote, L. and Epple, D. (1990) 'Learning curves in manufacturing', Science, Vol. 247, pp.920-924.

11 Sahal, D. (1980) 'Technological progress and policy', in Sahal, D. (Ed.): Research, Development, and Technological Innovation. Recent Perspectives in Management, Lexington Books, Lexington, Massachusetts.

12 Wright, G. (1997) 'Towards a more historical approach to technological change', The Economic Journal, Vol. 107, pp.1560-1567. 
13 Silverberg, G. (1991) 'Adoption and diffusion of technology as a collective evolutionary process', Technological Forecasting and Social Change, Vol. 39, pp.67-80.

14 Lahaye, N. and Llerena, D. (1997) 'Technology and sustainability: an organizational and institutional change', in Faucheux, S., Pearce, D. and Proops, J. (Eds.): Models of Sustainable Development, Edward Elgar, Cheltenham, United Kingdom.

15 Ghemawat, P. and Spence, M. (1995) 'Learning curve spillovers and market performance', The Quarterly Journal of Economics, Vol. 100, pp.839-852.

16 Duke, R. and Kammen, D. (1999) 'The economics of energy market transformation programs', The Energy Journal, Vol. 20, pp.15-64.

17 IEA (International Energy Agency) (2003) Creating Markets for Energy Technologies, International Energy Agency, Paris, France.

18 The term 'learning investments' refers to the cumulative amount of resources that must be invested in a given technology in order to make it move along its learning curve until it reaches the 'break-even' point and becomes competitive in the marketplace.

19 PCAST (President's Committee of Advisors on Science and Technology) (1999) Powerful Partnerships: The Federal Role in International Co-operation on Energy Innovation, President's Committee of Advisors on Science and Technology, Panel on International Co-operation in Energy Research, Development, Demonstration and Deployment, Washington, USA.

20 IPCC (Intergovernmental Panel on Climate Change) (2000) Methodological and Technological Issues in Technology Transfer, A Special Report of IPCC Working Group III. Intergovernmental Panel on Climate Change, Geneva, Switzerland, ISBN: 92-9169-112-7.

21 Martinot, E., Sinton, J. and Haddad, B.M. (1997) 'International technology transfer for climate change mitigation and the cases of Russia and China', Annu. Rev. Energy Environ., Vol. 22, pp.357-401.

22 IPCC (Intergovernmental Panel on Climate Change) (2001) Summary for Policymakers (SPM): Climate Change 2001: The Scientific Basis, IPCC, Geneva, Switzerland.

23 Messner, S. (1997) 'Endogenised technological learning in an energy systems model', Journal of Evolutionary Economics, Vol. 7, pp.291-313.

24 Mattsson, N. (1997) Internalising Technological Development in Energy Systems Models, Thesis for the Degree of Licentiate of Engineering. Chalmers University of Technology. Göteborg, Sweden.

25 Mattsson, N. and Wene C.O. (1997) 'Assessing new energy technologies using an energy system model with endogenized experience curves', Int J. Energy Research, Vol. 21, pp.385-393.

26 Gritsevskyi, A. and Nakićenović, N. (2000) 'Modelling uncertainty of induced technological change', Energy Policy, Vol. 28, pp.907-921.

27 Manne, A. and Richels, R. (2002) The Impact of Learning-by-doing on the Timing and Costs of $\mathrm{CO}_{2}$ Abatement, Working Paper, Stanford University.

28 Riahi, K. and Roehrl, R.A. (2000) 'Greenhouse gas emissions in a dynamics-as-usual scenario of economic and energy development', Technological Forecasting and Social Change, Vol. 63, pp.175-205.

29 Thomas, M., Post, H. and DeBlasio, R. (1999) 'Photovoltaic systems: an end-of-millennium review', Progress in Photovoltaics: Research and Applications, Vol. 7, pp.1-19.

30 Cody, G. and Tiedje, T. (1997) 'A learning curve approach to projecting cost and performance for photovoltaic technologies', in Future Generation Photovoltaic Technology: First NREL Conference, The American Institute of Physics, pp. 45-53.

31 Benner, J.P. and Kazmerski, L. (1999) 'Photovoltaics. gaining greater visibility', IEEE Spectrum, September, 1999 pp.35-42.

32 Shah, A., Torres, P., Tscharner, R., Wyrsch, N. and Keppner, H. (1999) 'Photovoltaic technology: the case for thin-film solar cells', Science, Vol. 285, pp.692-698. 
33 Kaplan, A. (1999) 'Generating interest, generating power: commercializing photovoltaics in the utility sector', Energy Policy, Vol. 27, pp.317-329.

34 Grübler, A. and Gritsevskyi, A. (1997) A Model of Endogenous Technological Change Through Uncertain Returns on Learning ( $R \& D$ and Investments), Paper presented at the International Workshop on induced Technical Change and the Environment. 26-27, June, International Institute for Applied Systems Analysis, Laxenburg, Austria. 


\section{Ordering Information}

Orders must include the publication number and should be sent to the Publications Department, International Institute for Applied Systems Analysis, A-2361 Laxenburg, Austria.

Telephone: +432236807

Telefax: +43223671313

E-mail: publications@iiasa.ac.at

A full list of IIASA publications is available at www.iiasa.ac.at/Publications 
International Institute for Applied Systems Analysis

Schlossplatz 1, A-2361 Laxenburg, Austria

$\Rightarrow$ Tel: +432236 807 Fax: +432236 71313

I I AS A www.iiasa.ac.at 